Proceedings

\title{
Effects of Worker-Soldier Termite Ratio on the Mortality Rate Exposed to Chlorfluazuron Baits ${ }^{\dagger}$
}

\author{
Wan Ahmad Syahir Wan Umar ${ }^{1}$ and Abdul Hafiz Ab Majid 1,*
}

\author{
1 Household \& Structural Urban Entomology Laboratory,Vector Control Research Unit, \\ School of Biological Sciences, Universiti Sains Malaysia, Penang, 11800 Minden, Malaysia \\ * Correspondence: abdhafiz@usm.my \\ + Presented at the 1st International Electronic Conference on Entomology (IECE 2021), 1-15 July 2021; \\ Available online: https://iece.sciforum.net/.
}

\begin{abstract}
Baiting is a preferred method of controlling termite populations by manipulating the foraging behavior and social existence of subterranean termites, in which food is transferred among termite workers and other nestmates via a process known as trophallaxis, which serves as a mechanism for the distribution of slow-acting toxicants across the entire termite colony. Thus, this study was conducted to evaluate the effect of termite ratio on the mortality rate of subterranean termite when exposed to chlorfluazuron bait. When termite was exposed to baits in a different set of ratios, there are differences in the mortality rate observed. In a series of bioassays, termites with a workerto-soldier ratio of 50 to 2 had the highest mortality rate. A higher mortality rate was observed in a ratio set of 50 personnel to 0 soldiers ( $p$ 0.05) when termites were given no choice of foods. As a result, a termite interaction (workers: soldiers) in the ratios of 50:0 and 50:02 is considered the best ratio for termite mutual interaction stability. Any disruption in the equilibrium of termite worker and soldier ratios would disrupt the termite interaction's harmony.
\end{abstract}

Keywords: termite baiting; chlorfluazuron; subterranean termite; termite ratio; mortality

Citation: Umar, W.A.S.W; Majid A.H.A. Effects of Worker-Soldier Termite Ratio on the Mortality Rate Exposed to Chlorfluazuron Baits, in Proceedings of the 1st International Electronic Conference on Entomology, 1-15 July 2021, MDPI: Basel Switzerland, doi:10.3390/IECE10366

Published: 30 June 2021

Publisher's Note: MDPI stays neutral with regard to jurisdictional claims in published maps and institutional affiliations.

\section{(cc) (i)}

Copyright: (c) 2021 by the authors. Submitted for possible open access publication under the terms and conditions of the Creative

Commons Attribution (CC BY) license

(http://creativecommons.org/licens es/by/4.0/).

\section{Introduction}

Termites are a serious problem in urban areas because they have negative economic consequences, such as lowering the value of buildings, destroying crops, and requiring household repairs due to termite damage [1]. Pest control professionals have used soil treatments to combat subterranean termite infestations since the 1900s [2].

Non-repellent termiticides (fipronil, chlorfenapyr, imidacloprid, chlorantraniliprole) and repellent termiticides (bifenthrin, permethrin, and cypermethrin) are the two types of soil treatments [2]. Bifenthrin and imidacloprid, which account for 65 percent of soil termiticides, contributed 90 percent of subterranean control [3]. Bifenthrin and imidacloprid, which account for 65 percent of soil termiticides, contributed 90 percent of subterranean control [3].

In October of 2000, pest control operators in Malaysia began using hexaflumuron baits to control subterranean termites [4]. In recent years, the use of baits in termite colony elimination has grown in popularity [5]. When compared to traditional barrier treatments, which have no effect on termite populations, these termite monitoring and baiting systems focus on eradication of termite colonies [6]. Baits must be found by termites, eaten, and the residual insecticide deposits horizontally transferred among colony members to ensure bait treatment achieves its goal [7]. When compared to standard chemical soil treatment, the active ingredients used in the baiting system have a low mammalian toxicity, have an impact only on targeted pest species, and use a relatively small amount of insecticide [8].

Chlorfluazuron is one of the benzoylphenylurea (BPU) group which contains a lethal chitin synthesis inhibitor (CSI) that can be applied on various orders of insects [9]. Mode of action of BPU which contains CSI, meaning that the synthesis of chitin in the insect 
cuticle is disrupted during the molting [10]. Several studies have successfully documented in eradication of lower termite species (rhinotermitids) using CSIs [11]-[14].

According to [15], as little as $1.1 \mathrm{~g}$ of bait matrix ( $=5.5 \mathrm{mg}$ noviflumuron) and fed for a single day were enough to eliminate colonies in $90 \mathrm{~d}$. This study suggests that only a small fraction of bait needed for a large laboratories colony to be eliminated [15]. Thus, the main purpose of this study, to discover the effect of termite ratio on the mortality rate of subterranean termite when exposed to chlorfluazuron bait in laboratory setting.

\section{Materials \& Methods}

\subsection{Termite Collection}

Coptotermes gestroi used in this experiment were collected in the Universiti Sains Malaysia (USM) campus. The colonies were maintained in underground monitoring stations containing nine wooden stakes (Araucaria $\mathrm{sp})(18 \mathrm{~cm} \times 1.5 \mathrm{~cm} \times 1.5 \mathrm{~cm})$ and corrugated cardboard. Nine wooden stakes and corrugated cardboard were replaced at every two weeks to maintain the colonies. Underground monitoring stations are hollow plastic containers (4.7 liter; $19.5 \mathrm{~cm} \times 19.5 \mathrm{~cm}$ ) which were buried in the soil [16]. Wooden stakes and corrugated cardboard were brought to Household and Structural Urban Entomology Laboratory (HSUEL) of School of Biological Science, USM for every two weeks. They were placed inside a plastic container, covered with black plastic and were kept in the dark at the room temperature $\left(28 \pm 2^{\circ} \mathrm{C}\right)$ and humidity $(\mathrm{RH} 70 \% \pm 10)$. Termites were separated and cleaned from the debris for the use of the experiment. The termites selected for bioassay were at least at their third instar. Termites were then, counted and transferred into a plastic dish ( $90 \times 15 \mathrm{~mm}$, Ideal Healthcare, Malaysia) for bioassays purposes.

\subsection{No-Choice Bioassay Set up}

One set of bioassay comprises six petri dishes ( $90 \times 15 \mathrm{~mm}$, Ideal Healthcare, Malaysia) for each of the treatment which included the control treatment. This method was referred and slightly modified from Bakaruddin [17]. All petri dishes were filled with a mixture of $25 \mathrm{~g}$ of sterile beach sand. For control bioassay, three wooden stakes with thickness of $0.5 \mathrm{~cm} \times 0.5 \mathrm{~cm}$ were placed at the center of petri dishes for each of three petri dishes. For the treatment bioassay, $1 \mathrm{~g}$ chlorfluazuron bait (Ensystex Sdn. Bhd.) mixed with $4 \mathrm{~mL}$ of distilled water to obtain doughy bait matrix and placed at each of the three petri dishes. Then, three set of termite ratio were prepared according to the workers: soldiers' ratio of; $50: 0 ; 50: 2 ; 50: 10$. The counted termite ratio were introduced at the center of the petri dishes for both control and treatment. All petri dishes were kept in the dark at $26 \pm 2^{\circ} \mathrm{C}$ and $65 \pm 5$ $\%$ relative humidity, and the rate of mortality for both control and treatment were counted and recorded at every 24 hours for 14 days. All petri dishes were sprayed at every 24 hours to moisten the sand beach. All the dead termites were removed from each of petri dishes during data counts. Figure 1 shows the set up for no- choice bioassays. 


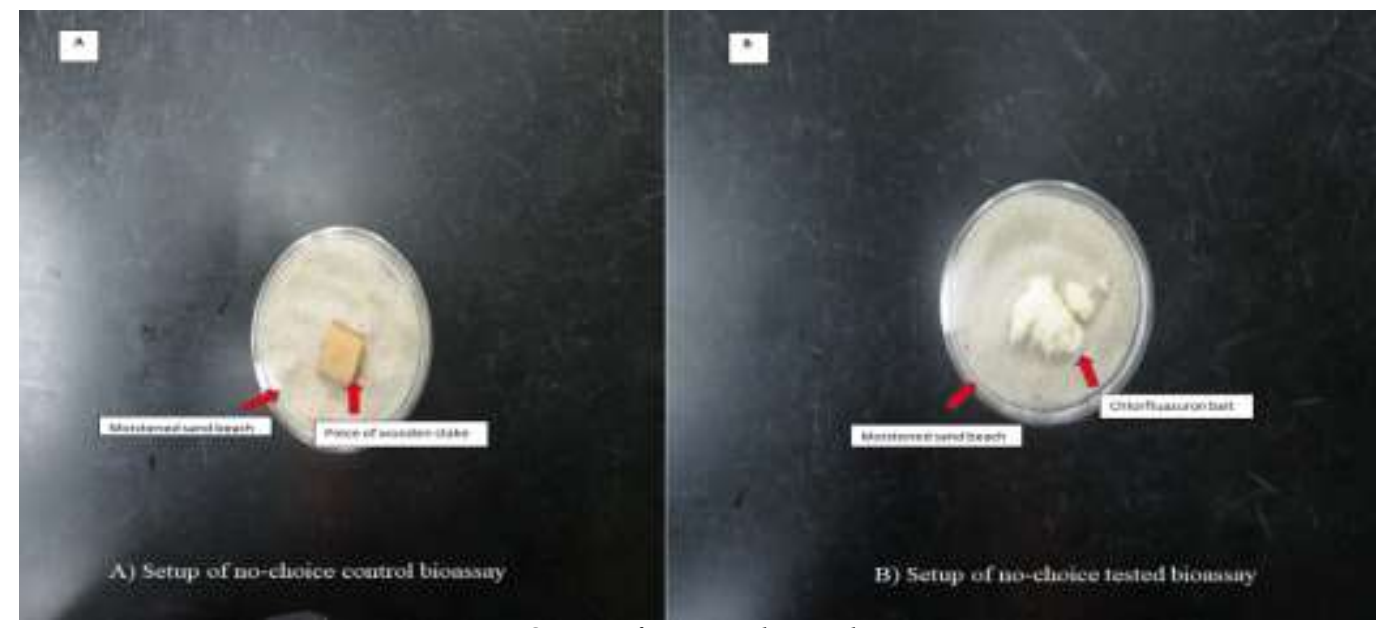

Figure 1. Set up for no- choice bioassays.

\subsection{Choice Bioassay Set up}

One set of bioassays made up of eighteen petri dishes $(90 \times 15 \mathrm{~mm}$, Ideal Healthcare, Malaysia) for each of the treatment which included the control treatment. One unit of bioassay was made up from three petri dishes connected via plastic tube (length: $4 \mathrm{~cm}$, diameter: $0.5 \mathrm{~cm}$ ) to each other. This method was referred and slightly modified from Acda, (2014). Twenty-five gram $(25 \mathrm{~g})$ of sterile beach sand were filled into all the petri dishes. For control bioassay, six wooden stakes with thickness of $0.5 \mathrm{~cm} \times 0.5 \mathrm{~cm}$ were placed at the center of petri dishes at each side (left and right) for each bioassay unit. While for the treatment bioassay, $1 \mathrm{~g}$ chlorfluazuron bait (Ensystex Sdn. Bhd.) mixed with $4 \mathrm{~mL}$ of distilled water to obtain doughy bait matrix and placed at the center of each three-unit bioassay (right vial) while in the left vial, wooden stakes with the same dimension were placed. Then, three set of termite ratio were prepared according to the workers: soldiers' ratio of; 50:0; 50:2; 50:10. The counted termite ratio were introduced at the center of the petri dishes for both control and treatment. All petri dishes were kept in the dark at $26 \pm 2{ }^{\circ} \mathrm{C}$ and $65 \pm 5 \%$ relative humidity, and the rate of mortality for both control and treatment were counted and recorded at every 24 hours for 14 days. All petri dishes were sprayed at every 24 hours to moisten the sand beach. All the dead termites were removed from each of petri dishes during data counts. Figure 2 shows the set up for choice bioassays.

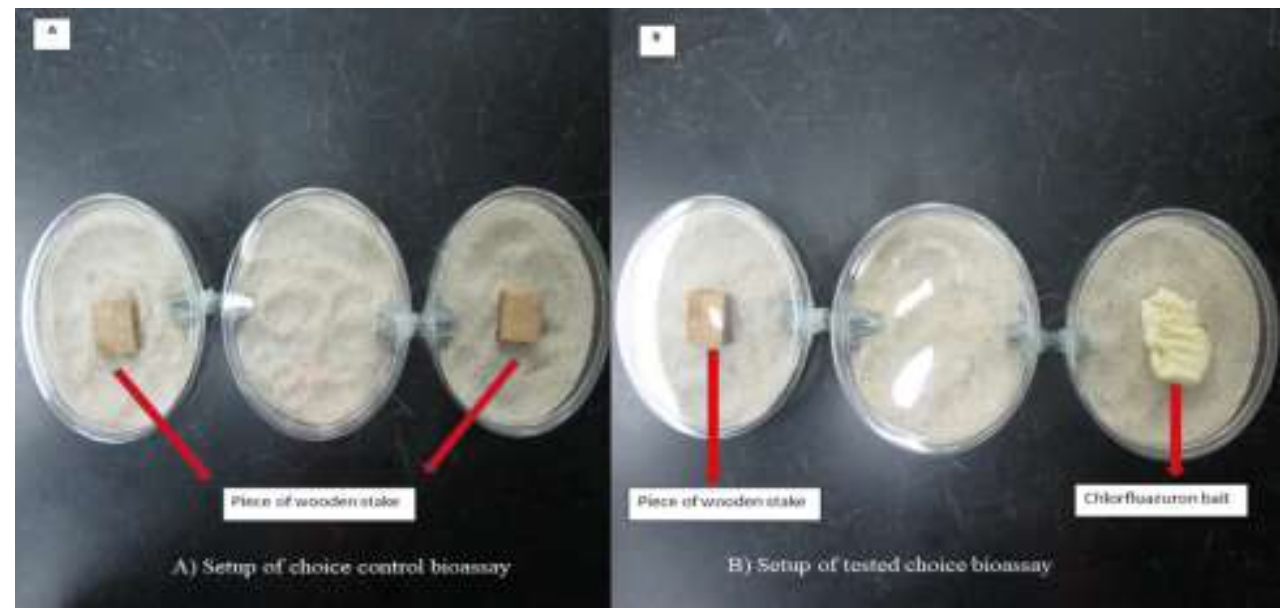

Figure 2. Set up for no- choice bioassays. 


\subsection{Data Analysis}

A T-test statistical analysis were done to evaluate effectiveness of chlorfluazuron baits to eliminate termite colony at each of the study sites. Total number of termites at zero day of the treatment were compared to the total termite number for the subsequent following weeks until the whole colony were eliminated. The percentage of termite number reduction were evaluated. Effect of different termite ratio in the no-choice and choice bioassays were analyzed by using factorial two-way ANOVA. Mortality difference in difference set of ratios (50:0; 50:02; 50:10) were determined by using SPSS 23 (IBM Corp., Armonk, NY, USA).

\section{Result}

\subsection{Choice bioassays}

A two-way ANOVA was conducted to examine the difference in mortality rate between replicates on the difference set of termite ratio. There was no significant difference in mortality in all vials among all sets of ratios $(\mathrm{p}=0.946)$. Termite mortality in the right vials and left vials are significant $(\mathrm{p}<0.05)$. The highest mortality of termites recorded in 50:2 ratio, followed by 50:10 and the least were in 50:0. The mortality of termites were always higher in right vials containing the baits compare to left vials which served wood. Figure 3 reveals the mortality rate in the choice bioassays of different set of ratios; 50:0; 50:2; and 50:10.

\subsection{No-Choice Bioassays}

A two-way ANOVA was conducted to examine the difference in mortality rate between control and replicate on the difference set of termite ratio. There was a statistically significant interaction between the effects of termite ratio and type of experiment on mortality rate of the termites, $\mathrm{F}(2,78)=3.429, \mathrm{p}=.037$. There was clear significant mortality in termite ratio of 50 workers: 0 soldiers and 50 workers: 2 soldiers ( $p=0.046)$, but no significant between 50 workers: 10 soldiers and 50 workers: 0 soldiers $(\mathrm{p}=0.129)$ and 50 workers:10 soldiers to 50 workers: 2 soldiers ( $\mathrm{p}=0.888$ ). In general, mortality in replicates (containing baits) were higher than the controls. Ratio 50 workers to 0 soldiers recorded highest mortality rate compared to another ratio. Figure 3 reveals the mortality rate in the bioassays of different set of ratios; 50:0; 50:2; and 50:10.
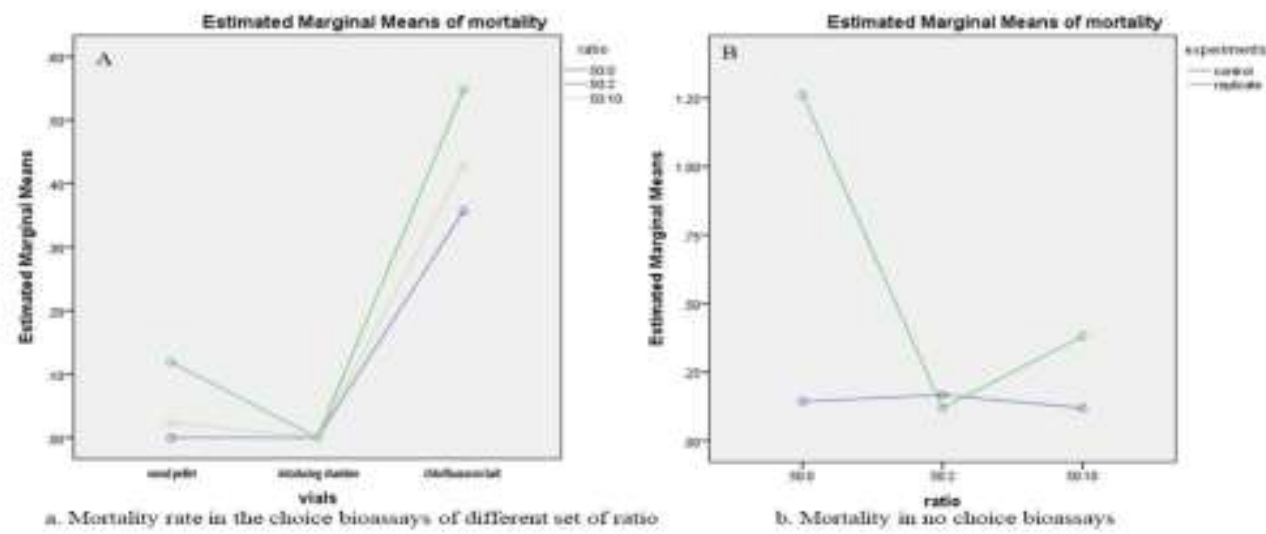

Figure 3. Mortality rate in the bioassays of different set of ratios; 50:0; 50:2; and 50:10 


\section{Discussion}

In no-choice bioassays, replicate vials have higher mortality rate compared to the control as the termite in replicates were exposed to the chlorfluazuron compared to wood in the controls. Mortality of termites were significant in 50:0 and 50:2 ratio while no significant at 50:10 ratio. According to Lee et al.[18], workers constituted $42.19 \%$ of the total population whereas soldiers make $14.16 \%$ from the total population of Macrotermes gilvus. In contrast to what Lee et al., [18], ratio 50:10 violates the ideal ratio of termite caste proportion while ratio 50:0 and 50:2 was still in the range of ideal ratio. The colony stability in most social insect species need to be maintain by allowing shifting of caste composition [18]. Thus, any violation of termite workers to termite soldier's ratio will disrupt the stability as observed in 50:10 ratio. However, in choice-bioassays, highest mortality was recorded by termite ratio 50:2 followed by 50:10 and the least in 50:0. The different arise as compared to the no-choice as in choice bioassays, termite were given to choose between wood or baits. In choice bioassay, mortality was always highest in baits vial compared to wood vial. This finding support by Rojas and Ramos [19], Formosan subterranean termite consumed more bait matrices compared to yellow pine in the two-choice foraging experiment. Besides, feeding deterrence induce by chitin synthesis inhibitors negate the termite to choose bait matrices [19]. Therefore, the mortality observed higher in bait vials compare to wood vials.

Ratio 50 workers to no soldiers recorded highest mortality rate compared to the other two ratios. This is because when there are no soldiers, workers tend to be more focus on consuming the baits and less burden as the workers do not need to feed the soldiers. This statement coincides with Kuswanto et al., [20] which stated that any extra number of soldiers will cause stress to the colony as the workers need to feed the soldiers. Thus, when there are no soldiers, workers will consume more bait and indirectly explained the higher mortality rate in 50:0 termite worker to termite soldier ratio. However, ratio 50:10 worker to soldier ratio recorded the second highest mortality. Soldiers are responsible for guarding the colony and its nest mates [1] but need to be feed by termite workers [20] as they cannot feed on their own. The workers in this set of ratios will need to consume more as they need to feed the soldiers which is the highest number (10) compared to the other ratio thus such interaction between workers and soldiers increased the mortality rate in 50:10 ratio.

\section{Conclusion}

Distinct termite ratios result in different situations for workers and soldiers to interact in. In order to retain their social responsibilities and work as a single colony unit, termites will always follow the optimal set of termite caste composition. As a result, a termite interaction (workers: soldiers) ratio of 50:0 and 50:02 is regarded the ideal ratio for termite mutual interaction stability. The harmony of termite interaction would be disrupted if the quantity of termite workers and soldiers is out of balance.

Author Contributions: Conceptualization: A.H.A.M.; methodology, A.H.A.M., and W.A.S.W.U; validation, A.H.A.M., and W.A.S.W.U.; formal analysis, W.A.S.W.U.; investigation, A.H.A.M., and W.A.S.W.U.; resources, A.H.A.M.; data curation, A.H.A.M., and W.A.S.W.U; writing - review and editing A.H.A.M., and W.A.S.W.U.; supervision, A.H.A.M.; and project administration, A.H.A.M.; funding acquisition. A.H.A.M. All authors have read and agreed to the published version of the manuscript. 
Funding: This research was funded by Industrial Research Grant [304/PBIOLOGI/6501078/C132] and Research University Grant [1001/PBIOLOGI/8011104]..

Acknowledgments: In this section, you can acknowledge any support given which is not covered by the author contribution or funding sections. This may include administrative and technical support, or donations in kind (e.g., materials used for experiments).

Conflicts of Interest: We would like to Thank Ensystex (Malaysia) Sdn Bhd for the chlorfluazuron termite bait supplies for this study. Our appreciation goes to Universiti Sains Malayisa Research [University Grant [Rui: 1001/PBIOLOGI/8011104] for the support and funding

\section{Reference}

[1] S. Ghaly, A., and Edwards, “Termite damage to buildings: Nature of attacks and preventive construction methods.," Am. J. Eng. Appl. Sci., 2011, vol. 4, pp. 187-200.

[2] N. Y. Su, “Technological needs for sustainable termite management,” 2011, vol. 58, pp. 229-239.

[3] B. W. Koehler, P. G., Pereira, R. M., \& Jordan, "New techniques for subterranean termite control," in Proceedings of the Seventh International Conference on Urban Pests, 2011, pp. 1-4.

[4] C. Y. Lee, "Subterranean termite pests and their control in the urban environment in Malaysia.," Sociobiology, 2002, vol. 40, pp. 3-10.

[5] H. H. Lee, C. Y., Foo , F. K., How, Y. F., Hu, J., Koh P, K. H., Neoh, K. B., and Ho J, “Termites of Singapore: A Scientific Guide for Pest Management Professionals.," Singapore Pest Manag. Assoc. Singapore, , 2014, pp. 8-33.

[6] W. L. Lax, A. R., and Osbrink, “United States Department of Agriculture-agriculture research service research on targeted management of the Formosan subterranean termite Coptotermes formosanus Shiraki (Isoptera: Rhinotermitidae).," Pest Manag. Sci., 2003, vol. 59, pp. 788-800.

[7] M. E. Scharf, “Termites as targets and models for biotechnology.," Annu. Rev. Entomol., 2001, vol. 60, pp. 77-102.

[8] S. Broadbent, "A stand-alone termite management technology in Australia.," Urban pest Manag. an Environ. Perspect., 2011, pp. 145-155.

[9] J. E. Hajjar, N. P. and Casida, "Structure-activity relationships of benzoyl phenyl urea as toxicants and chitin synthesis inhibitors in Oncopeltus fasciatus.," Pestic. Biochem. Physiol, 1979, vol. 11, pp. 33-45.

[10] S. J. Yu, The toxicology and biochemistry of insecticide. Boca Raton, FL.: CRC Press, 2008.

[11] C. J. Peters, B. C., and Fitzgerald, "Field evaluation of the bait toxicant chlorfluazuron in eliminating Coptotermes acinaciformis (Froggatt)(Isoptera: Rhinotermitidae).," J. Econ. Entomol., 2003, vol. 94, pp. 1828-1831.

[12] E. M. Cabrera, B. J., and Thoms, "Versatility of baits containing noviflumuron for control of a structural infestations of Formosan subterranean termites (Isoptera: Rhinotermitidae).," Fla. Entomol, 2006, vol. 89, pp. $20-31$.

[13] T. A. Evans, "Rapid elimination of field colonies of subterranean termites (Isoptera: Rhinotermitidae) using bistrifluron solid bait pellets.," J. Econ. Entomol, 2010, vol. 103, pp. 423-432.

[14] V. R. Haverty, M. I., Tabuchi, R. L., Vargo, E. L., Cox, D. L., Nelson, L. J., and Lewis, “Response of Reticulitermes hesperus (Isoptera: Rhinotermitidae) colonies to baiting with lufenuron in northern California," J. Econ. Entomol., 2010, vol. 103, pp. 770-780.

[15] N. Y. Chouvenc, T., \& Su, “Subterranean termites feeding on CSI baits for a short duration still results in colony elimination.," J. Econ. Entomol., 2017, vol. 110, no. 6, pp. 2534-2538.

[16] A. . Ab Majid, A. H., \& Ahmad, "Preliminary field efficacy of transfer effect of slow acting termiticide (imidacloprid) on subterranean termite population (Coptotermes gestroi) (Wasmann) (Isoptera: Rhinotermitidae).," J. Biosci., 2008, vol. 19, no. 2, pp. 101-106. 
[17] A. H. Bakaruddin, N. H., Dieng, H., Sulaiman, S. F., \& Ab Majid, “Evaluation of the toxicity and repellency of tropical plant extract against subterranean termites, Globitermes sulphureus and Coptotermes gestroi.," Inf. Process. Agric., 2018, vol. 5, no. 3, pp. 298-307.

[18] C. Y. Lee, C. Y., Neoh, K. B., and Lee, "Caste composition and mound size of the subterranean termite Macrotermes gilvus (Isoptera: Termitidae: Macrotermitinae).," Ann. Entomol. Soc. Am., 2012, vol. 105, pp. 427-433.

[19] J. A. Rojas, M. G., and Morales-Ramos, "Bait matrix for delivery of chitin synthesis inhibitors to the Formosan subterranean termite (Isoptera: Rhinotermitidae).," J. Econ. Entomol., 2001, vol. 94, pp. 506-510.

[20] R. Kuswanto, E., Ahmad, I., and Dungani, “Threat of subterranean termites attack in the Asian countries and their control: A review.," Asian J. Appl. Sci., 2015, vol. 8, pp. 227-239. 